\title{
Prevention Trials in Women at Moderate Risk of Breast Cancer
}

\author{
Gunter von Minckwitz ${ }^{a}$ Sibylle Loibla Silvia Gimeno ${ }^{a} \quad$ Patricia Segura-Eicke $^{a}$ \\ Wolfgang Eiermann ${ }^{b}$ Manfred Kaufmann ${ }^{c}$ \\ a GBG Forschungs $\mathrm{GmbH}$, Neu Isenburg, \\ b Frauenklinik vom Roten Kreuz, München, \\ c Universitätsfrauenklinik, Johann-Wolfgang-Goethe-Universität, Frankfurt/M., Germany
}

\section{Key Words}

Prevention · Breast cancer · Clinical trials · SERMs

\section{Summary}

The primary goal of most protocols of past and present mammary cancer clinical trials is the reduction of breast cancer incidence. The assumption that the selective estrogen receptor modulator (SERM) tamoxifen could prevent mammary cancer resulted from the experience obtained in palliative and adjuvant treatments. Several prevention clinical trials involve this SERM, e.g. P1, IBIS I, Royal Marsden Hospital Tamoxifen Prevention Trial, Italian Randomized Trial Among Hysterectomized Women. Second-generation trials tested other types of substances, such as aromatase inhibitors which were included in the IBIS II trial. Other trials investigate alternative SERMs, such as raloxifene, arzoxifene and lasofoxifene, as well as endocrine substances, such as gonadotropinreleasing hormone agonists and enzyme inhibitors (e.g. Cox-2 cyclooxigenases).

\section{Introduction}

The goal of chemoprevention [1] is to hinder the development of established or preliminary breast disease, finally attempting to reduce mortality. These chemoprevention measures fundamentally lack a clear concept of establishing which patient group should receive a particular substance. The choice can depend on the risk profile or on predictive factors. It would be

\author{
Schlüsselwörter \\ Prävention · Brustkrebs · Klinische Studien · SERMs
}

\section{Zusammenfassung}

Das Hauptziel von sowohl frühen als auch aktuellen klinischen Studien zum Mammakarzinom ist die Verringerung der Inzidenz der Erkrankung. Erfahrungen mit SERMs (selektive Östrogenrezeptor-Modulatoren) wie Tamoxifen in der adjuvanten sowie in der palliativen Situation haben zu der Annahme geführt, dass Tamoxifen auch in der medikamentösen Prävention von Brustkrebs wirksam sein kann. Präventionsstudien mit Tamoxifen sind z. B. P1, IBIS I, Royal Marsden Hospital Tamoxifen Prevention Trial und Italian Randomized Trial bei hysterektomierten Patientinnen. In Studien der zweiten Generation wurde eine andere Substanzklasse geprüft, wie z.B. ein Aromatase-Hemmer bei IBIS II. Weitere Studien untersuchen die Wirksamkeit von anderen SERMs wie Raloxifen, Arzoxifen und Lasofoxifen. Aber auch endokrin wirksame Substanzen wie Gonadotropin-ReleasingHormone-Agonisten und Enzym-Inhibitoren (z.B. COX-2Cyclooxygenasen) werden im Rahmen der Möglichkeiten zur Chemoprävention untersucht.

much more reasonable to choose the treatment according to selection criteria related to the drug's mode of action. Notwithstanding the intensive research in this field, the identification of predictive breast cancer markers for currently available drugs has yet not been achieved.

Other medical fields, such as the prevention of heart attacks, represent positive examples of treatment. Here, patients with high blood pressure can receive antihypertensive treatment.

\begin{tabular}{|c|c|c|}
\hline KARGER & (c) 2006 S. Karger GmbH, Freiburg & $\begin{array}{l}\text { Dr. Silvia Gimeno } \\
\text { GBG Forschungs GmbH }\end{array}$ \\
\hline $\begin{array}{l}\text { Fax +497614520714 } \\
\text { E-mail Information@Karger.de } \\
\text { www.karger.com }\end{array}$ & $\begin{array}{l}\text { Accessible online at: } \\
\text { www.karger.com/brc }\end{array}$ & $\begin{array}{l}\text { Schleussnerstr. } 42 \\
63263 \text { Neu Isenburg, Germany } \\
\text { Tel. +49 6102 798-7435, Fax -7440 } \\
\text { E-mail gimeno@germanbreastgroup.de }\end{array}$ \\
\hline
\end{tabular}


Patients with high cholesterol values receive anti-lipemic treatment, and those with high glucose values insulin. The relation between modified laboratory values and the recognition of coronary scleroses as surrogate marker was of primary importance to the development of the above mentioned proceedings. Similar causalities should be detected and tested in breast cancer. Longer follow-up periods and bigger groups of participants are required to establish a reduction in breast cancer mortality, compared to the reduction in breast cancer incidence. Thus, the primary goal of most study protocols is the reduction of breast cancer incidence. Due to the high costs arising in prevention studies, it is clear that these studies can usually not be repeated and should aim to provide the required information about the treatment drug.

\section{First-Generation Trials Using Tamoxifen}

The assumption that the selective estrogen receptor modulator (SERM) tamoxifen could prevent mammary cancer results from the experience obtained in palliative and adjuvant treatments. Tamoxifen alone or in combination with chemotherapy proved to be effective in advanced mammary cancers. It reduces the frequency of relapses, prolongs life when administered postoperatively in stage I or II cancer and reduces $47 \%$ of the incidence in contralateral mammary tumors. Besides, it can be administered to mammary cancer patients safely and with high compliance due to the positive balance between risk and benefit. Therefore, tamoxifen is fulfilling all the requirements to be tested in the prevention studies. Currently, results are available from 4 randomized studies.

\section{The NSABP Breast Cancer Prevention Trial (BCPT)-P1}

This study by the National Surgical Adjuvant Breast and Bowel Project (NSABP) [2] recruited, between 1992 and 1997, 13,388 patients. Eligible were women between 30 and 59 years of age with a 5-year breast cancer risk of at least $1.66 \%$ calculated through the Gail Model. Women aged 60 years or older and those having undergone surgery for lobular carcinoma in situ (LCIS) were also allowed to participate. All participants had to show a normal mammography performed within 180 days prior to entry. The study was finished early and unblinded due to the observed significant reduction in breast cancer incidence and the pressure exerted by the participants' representative. As the women participating in the placebo arm were allowed to receive tamoxifen, it was impossible to establish through this study a reduction in breast cancer mortality. When the results of the Breast Cancer Prevention Trial (BCPT) were announced, they showed that researchers had found a $49 \%$ reduction in invasive breast cancer incidence among participants at increased risk of the disease who took tamoxifen. The study results also showed a $45 \%$ reduction in non-invasive breast cancer incidence (fig. 1). Women with the BRCA 1 mutation appeared to not benefit from tamoxifen in

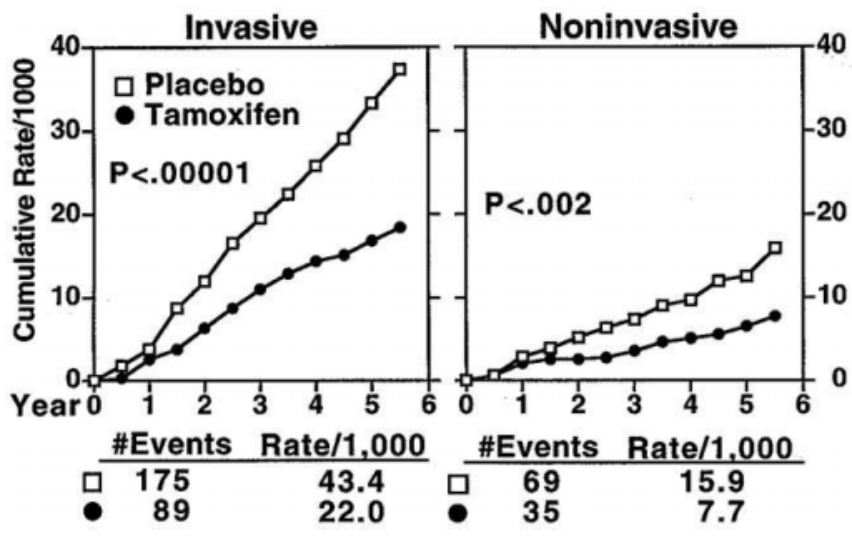

Fig. 1. Cumulative rate of invasive und non-invasive mammary carcinoma in the participants of the P1 trial.

terms of risk reduction. For women with lower risk, e.g. older than 60 years, tamoxifen seemed to be advantageous as a preventive measure.

\section{The Royal Marsden Hospital Tamoxifen Prevention Trial}

Between 1986 and 1996, 2,494 women aged 30-70 years with a family history of breast cancer were randomized to a doubleblind trial [3]. Over a period of 8 years, participants received either placebo or $20 \mathrm{mg}$ tamoxifen daily. Entry criteria were mainly based on the family risk burden. Each participant had to have at least i) 1 first-degree relative diagnosed with breast cancer under the age of 50 or, ii) 1 first-degree relative with bilateral mammary cancer or, iii) 1 first-degree relative diagnosed with breast cancer at any age and a further first- or second-degree relative with breast cancer or, iv) 1 first-degree relative diagnosed with breast cancer at any age and herself presenting a benign histology resulting from a core biopsy.

No overall difference in breast cancer occurrence was observed among the 2 groups. Hormone replacement therapy parallel to the study medication was carried out in 1,030 participants. When started before the study, it increased the risk of breast cancer by a factor of $1.9(95 \% \mathrm{CI}: 1-3, \mathrm{p}=0.04)$. If, on the other hand, it began during the study, it reduced the risk by a factor of 0.4 (95\% CI: $0.2-0.7, p=0.001)$. Another profitable advantage of the tamoxifen therapy was the reduction $(10 \%)$ of the cholesterol serum level, only observed in the participants of the tamoxifen group. Serious adverse events, the occurrence of other carcinomas, thromboembolisms, or non-mammary-cancer-related deaths were seldom observed.

\section{The Italian Randomized Trial Among Hysterectomized Women}

Between 1992 and 1997, a prevention trial organized by the National Cancer Institute of Milan, Italy, recruited 5,408 women [4]. Participants were 35-70 years of age, and hysterectomized with or without annexectomy. Excluded were women 


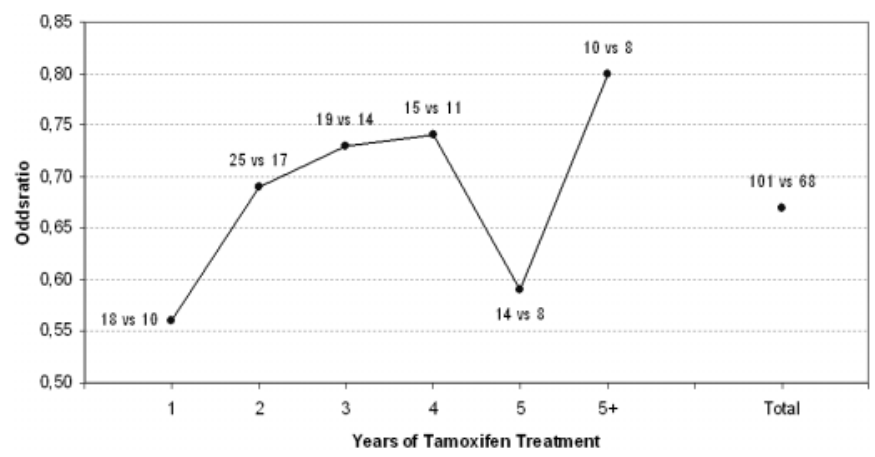

Fig. 2. Risk rate for breast cancer incidence during IBIS I participation. Placebo vs. tamoxifen [5].

with severe concomitant disease, heart disease, endometriosis and deep vein thromboses. The patients in this double-blind, placebo-controlled trial received either placebo or $20 \mathrm{mg}$ tamoxifen daily for a period of 5 years. At the time of the evaluation for the first publication, 3,837 women were still receiving study medication and 1,442 had dropped out, $60 \%$ of them in the first year of their participation. Only 149 participants had finished their 5-year treatment. The low risk profile observed in this trial results from the high rate of pre-trial ovariectomies. During the 4 years of observation, the mammary cancer occurrence rate was approximately the same (22 in the placebo group against 19 in the treatment group). If we limit the group examined to those who had received treatment for at least 1 year, then there were 19 breast cancer cases in the placebo group compared to 11 in the tamoxifen group. The positive effect of tamoxifen shows to be higher in women parallely treated with hormone replacement drugs.

The International Breast Cancer Intervention Study 1 (IBIS I) The 4th tamoxifen prevention trial was carried out in Great Britain and Australia between the years 1992 and 2001 [5]. 7,139 women between 35 and 70 years of age were recruited into 2 groups, placebo and tamoxifen. The inclusion criteria were based on breast cancer risk factors. Women with previous mammary cancer, deep vein thromboses, and pulmonary emboli treated with anti-coagulants, or a life expectancy lower than 10 years were excluded from the study.

An increased risk (factor 2.5) of thromboembolic events was observed as a mayor side effect in the tamoxifen group. In the same group, there was a $21 \%$ increase in the following events: hot flushes, abnormal vaginal bleeding, candida infections. No difference was observed between the 2 groups in the occurrence of bone fractures. The increased cancer incidence rate is shown in figure 2 [5]. This trial provided answers to some questions raised in the former trials: The authors recommend to stop tamoxifen therapy before an operation and not to reinitiate it until after a 3-month break. Although the occurrence of endometrial carcinoma was not high, other endocrine substances with a more favorable anti-estrogen profile should

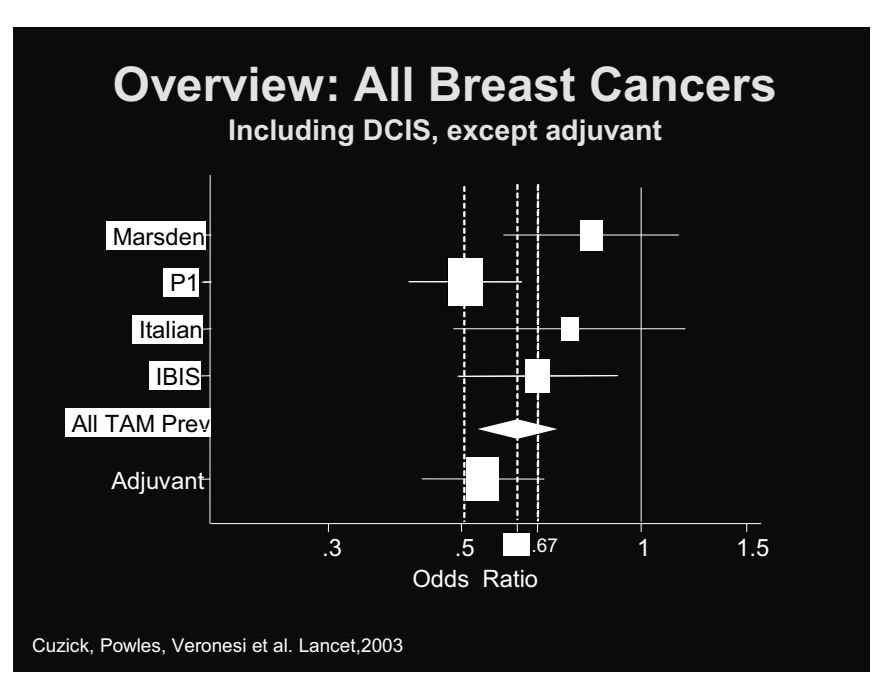

Fig. 3. Overview of all breast cancers including DCIS except adjuvant. Comparison IBIS I, P1, Italian and Marsden trials [6].

also be tested as chemopreventive drugs. An overview of the results is shown in figure 3 [6].

Although many studies have showed that tamoxifen successfully reduces the development of breast cancer, its side-effect profile is not optimal thus raising a series of questions. Current strategies aim to achieve safe administration of tamoxifen (adequate thrombosis prophylaxis, exclusion of risk patients, lower doses etc.). Other strategies consist of replacing tamoxifen with other SERMs with a different action spectrum, such as aromatase inhibitors.

\section{Second-Generation Trials}

\section{Using Aromatase Inhibitors}

\section{IBIS II Prevention}

After considering the advantages and risks of tamoxifen through the results obtained in the IBIS I trial, Cancer Research UK decided that tamoxifen was not beneficial for women at medium risk of breast cancer. Besides, in Europe, tamoxifen is not approved to be used in the prevention of mammary cancer. The IBIS II Prevention Trial includes a placebo in the control arm. The new tested substance is the aromatase inhibitor anastrozole. Anastrozole appears to reduce even more the development of contralateral breast tumors. Apart from this, less thromboembolic events and less change in the endometrium are observed. Special attention should be given to the higher possibility of bone fractures and the reduction in performance. In Germany, the trial is coordinated by the German Breast Group (GBG). The design of the IBIS II Prevention Study (worldwide 6,000 patients planned) is as follows: postmenopausal women aged 40-70 years, at medium risk of breast cancer, are randomized to either place- 
Fig. 4. The design of the IBIS II Prevention Trial.

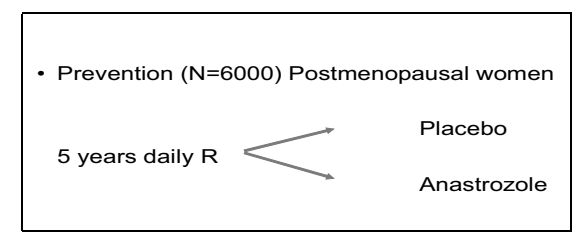

bo or $1 \mathrm{mg}$ anastrozole daily for a period of 5 years. Entry criteria include: family risk, no children or first live birth at age 30 or older, mammographic opacity of $50 \%$, having undergone surgery for LCIS, atypical ductal or lobular hyperplasia $(\mathrm{ADH})$ or ductal carcinoma in situ (DCIS). Figure 4 shows the trial design. The current international recruitment is shown in table 1 .

\section{Using Raloxifene}

\section{Multiple Outcome Raloxifene (MORE trial)}

The MORE trial [7] is a multicenter, randomized, doubleblind trial primarily designed to establish the effect of a 3-year raloxifene treatment on the risk of bone fractures in postmenopausal women. The reduction in breast cancer through the treatment with the SERM raloxifene was the second goal in the trial. Between 1994 and 1998, 7,705 women were recruited. Among them, 2,576 received a placebo, 2,557 $60 \mathrm{mg}$ raloxifene and 2,572 $120 \mathrm{mg}$ raloxifene daily. Conditions to participate included at least 2 years of menopause, age $\leq 80$ years and osteoporosis. Excluded were those women with suspicion of or confirmed mammary or endometrial cancer, strokes, postmenopausal bleeding or thromboembolism. The treatment with raloxifene was carried out in 5,901 women during 3 years.

Hot flushes were the most common side effect observed. No difference in the breast cancer incidence was seen between the 2 raloxifene groups. A similar effect as that of tamoxifen was detected regarding the non-response of hormone-receptornegative carcinomas to the raloxifene therapy. In 7,290 women blood samples were collected previous to the trial. The estrogen concentration in blood was measured in order to later correlate it with the appearance of mammary tumors. Comparing the placebo and raloxifene group of women with estrogen values of $>10 \mathrm{pM} / \mathrm{l}$, the later presented $76 \%$ less cases of breast cancer. Raloxifene showed not only a higher efficacy than tamoxifen but also a more favorable side effect spectrum.

\section{Raloxifene Use for The Heart (RUTH Trial)}

This trial [8] can be summarized as follows: patients receive either $60 \mathrm{mg}$ raloxifene or placebo daily. Entry criteria include: more than 54 years of age, more than 1 year of menopause, presenting a normal mammography, Gail risk $>1.66 \% ; 35 \%$ $(=3,535)$ women. Primary outcomes include CHD events and invasive breast cancer, with an accrual between 6/98 and 8/00 of 10,101 women with CHD or at risk of CHD.
Table 1. International recruitment from the IBIS II trial

\begin{tabular}{|c|c|c|c|}
\hline \multirow[t]{2}{*}{ Country } & \multicolumn{3}{|l|}{ Patients, n } \\
\hline & Prevention & DCIS & Total \\
\hline Australia and New Zealand & 28 & 6 & 34 \\
\hline Austria & 0 & 33 & 33 \\
\hline Belgium & 30 & 52 & 82 \\
\hline Chile & 0 & 5 & 5 \\
\hline Denmark & 19 & 0 & 19 \\
\hline Germany & 88 & 166 & 254 \\
\hline Egypt & 3 & 0 & 3 \\
\hline Finland & 75 & 5 & 80 \\
\hline France & 0 & 139 & 139 \\
\hline Hungary & 28 & 11 & 39 \\
\hline India & 0 & 1 & 1 \\
\hline Ireland & 25 & 12 & 37 \\
\hline Italy & 35 & 107 & 142 \\
\hline Malta & 24 & 3 & 27 \\
\hline Pakistan & 4 & 0 & 4 \\
\hline Peru & 2 & 0 & 2 \\
\hline Portugal & 28 & 0 & 28 \\
\hline UK & 829 & 217 & 1,046 \\
\hline Switzerland & 9 & 5 & 14 \\
\hline Turkey & 0 & 4 & 4 \\
\hline International totals & 1,227 & 766 & 1,993 \\
\hline
\end{tabular}

DCIS $=$ Ductal carcinoma in situ

\section{STAR Trial}

Early 1999, the NSABP obtained financial support from the National Cancer Institute to carry out a subsequent trial to the P1, the Study on Tamoxifen and Raloxifene, STAR Trial. The STAR Trial, one of the biggest prevention trials carried out until now, recruited 19,747 women until October 2005. Among them, women over 35 years with increased risk of mammary cancer determined by their age, a family history of breast cancer, personal medical history, age at first menstrual period, and age at first live birth, were randomized into 2 treatment groups, either raloxifene $(60 \mathrm{mg})$ or tamoxifen $(20$ $\mathrm{mg}$ ) daily during 5 years. The STAR study design is shown in figure 5 .

The current results were obtained from 19,471 women with fully documented compliance [9]. Both drugs reduced the risk of breast cancer by $50 \%$. The number of invasive breast cancers in both groups of women were statistically equivalent. Among the 9,745 women in the raloxifene group, 167 developed invasive breast cancer, compared to 163 of 9,726 women in the tamoxifen group. More than half of the women who joined STAR had had a hysterectomy and, therefore, were not at risk of uterine cancer. 36 of 4,732 women with a uterus who were assigned to take tamoxifen developed uterine cancers (mainly endometrial cancer) compared to 23 of 4,712 women who were assigned to take raloxifene. Women in the raloxifene group had $29 \%$ fewer deep vein thromboses and pulmonary embolisms than women in the tamoxifen group. The 


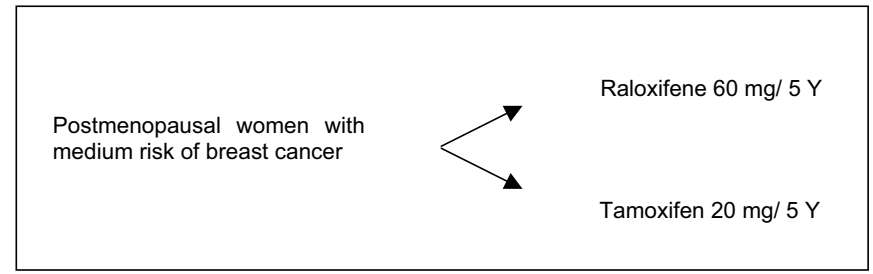

Fig. 5. The design of the STAR trial.

number of strokes occurring during the trial in both groups of women was statistically equivalent: 53 of 9,726 women in the tamoxifen group and 51 of 9,745 women in the raloxifene group. There was no difference in deaths from strokes: 6 of 9,726 women in the tamoxifen group and 4 of 9,745 women in the raloxifene group. Women at increased risk of stroke (those with uncontrolled hypertension or uncontrolled diabetes, or a history of stroke, transient ischemic attack) were not eligible to participate in STAR. While tamoxifen has been shown to reduce, by half, the incidence of LCIS and DCIS, raloxifene did not have an effect on these diagnoses. Of the 9,726 women taking tamoxifen, 57 developed LCIS or DCIS, compared to 81 of 9,745 taking raloxifene. This result confirms data reported in 2004 in a large study of raloxifene, the Continued Outcomes Relevant to Evista (or CORE Trial). The trial was, according to current information, unblinded. Women assigned to raloxifene will continue to be provided with the drug until they have completed 5 years of treatment. Those women assigned to tamoxifen can choose to continue taking tamoxifen or to receive raloxifene to complete their 5 years of treatment.

\section{Using Compounds with Preventive Potential}

\section{Arzoxifene and Lasofoxifene}

Preclinical data on the SERM arzoxifene in rats [10] established that it prevents the loss of bone mineral density (BMD)and reduces serum cholesterol by $44-59 \%$. In nude mice, a dose-dependent inhibition of MCF7 xenograft was observed. 2 mayor clinical trials on advanced disease were carried out: the European Study [11] and the US Study [12]. The study design and objective responses (WHO) are shown in figure 6.

Preclinical data on the SERM lasofoxifene [13] showed that it preserves bone mass and strength, decreases low-density lipoprotein cholesterol, inhibits breast cancer in animals, reverses vaginal atrophy and does not induce uterine hypertrophy in animals.

Postmenopausal Evaluation and Risk-Reduction With Lasofoxifene (PEARL Trial)

8,556 postmenopausal healthy women aged $60-80$ years with low BMD were randomized to $0.25 \mathrm{mg}$ or $0.5 \mathrm{mg}$ lasofoxifene daily or placebo. Excluded were women who had metabolic

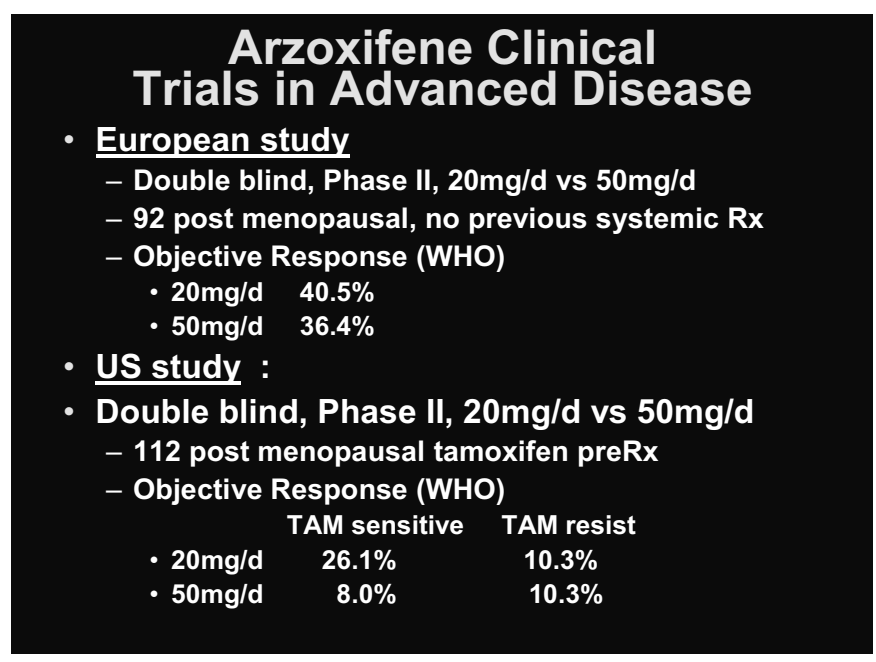

Fig. 6. Study design and objective response (WHO) from the European and US trials.

bone disease, were taking approved medications for osteoporosis or have had a recent fracture. There were 113 study sites in 32 countries on 6 continents. Primary objectives were: incidence of new vertebral fractures and incidence of invasive breast cancer. Secondary objectives included: effects on estrogen-receptor-positive invasive breast cancer, breast density, any clinical fractures, any non-spinal fractures, any hip fractures, major CHD events, and mortality in general.

\section{GnRH in Premenopausal Women}

The current endocrine measures appear not to be convincing for young women with a high genetic mammary cancer burden. Besides, different trials showed that breast cancers associated with BRCA 1 were only in few cases hormone-receptor-positive [14]. As measures such as prophylactic mastectomy, although very effective, create long-term disadvantages, it is of major importance to find a medical treatment for these cases. Gonadotropin-releasing hormone ( $\mathrm{GnRH})$ agonists can suppress ovarian function in premenopausal women. In $90 \%$ of cases, the level of plasma estradiol is reduced to that of postmenopausal women [15].

Recently, data were reported giving evidence of the prophylactic effect of GnRH agonists. These data resulted from a trial involving goserelin as adjuvant treatment in premenopausal women with primary breast cancer. In 2 trials with a total of 3,000 patients, it was proved that goserelin reduced the rate of contralateral mammary cancer by $50 \%$ [16, 17]. As a result, an international study group created different concepts of the use of GnRH analogues for the prevention of breast cancer in premenopausal women with strong family burden or BRCA mutation (GISS, RAZOR).

\section{Cox-2 Inhibitors}

Cyclooxygenases (Cox) are bifunctional enzymes necessary for the synthesis of prostaglandins. Cox-2 cannot be detected 
in normal tissue. On the other hand, in inflammatory neoplastic tissues Cox-2 is induced by cytokines, growth factors and oncogenes, with parallel stimulation of the prostaglandin synthesis $[18,19]$.

Non-steroidal antiphlogistic/antirheumatic drugs (non-steroidal anti-inflammatory drugs, NSAID), such as acetylsalicylic acid, diclofenac, indometacine, ibuprofene, inhibit both Cox synthetases, resulting in the loss of mucous membrane protection and causing gastric ulcer and bleeding. Cox-2 inhibitors (e.g. celecoxib, refecoxib) act selectively against the Cox-2 [20]. Clear overexpression of Cox-2 is detected in DCIS and invasive human mammary cancers. In rats, administration of celecoxib results in strong reduction in the manifestation and tumor volume of mammary cancer compared to the control group $(68 \%, 81 \%, \mathrm{P}<0.001)$ [21]. First indications of a protective effect of NSAID against mammary cancer were given by a patient with rheumatoid arthritis. It was observed that patients regularly taking NSAID for pain relief seldom present mammary tumors [22].

A number of randomized, double-blind and placebo-controlled trials reported that NSAID could significantly reduce the appearance of new polyps in familial adenomatous poly- posis (FAP). Currently, based on these data, new trials (e.g. REACT Trial) with the Cox-2 inhibitor celecoxib in the adjuvant therapy and for the prevention of mammary cancer are under way.

\section{Conclusion}

Of the prevention trials involving postmenopausal women, IBIS II is the only study currently also being carried out in Europe. Through the dedicated support of the participating centers, it was shown that chemo-preventive treatment for women at moderate/high risk of mammary cancer is a realistic possibility.

Comparing the trials involving premenopausal women, the P1, although famous, lacked a real placebo arm. The study was unblinded at an early stage, and patients in the placebo arm continued with tamoxifen thus not providing follow-up information about breast cancer mortality. The GISS trial (goserelin + ibandronate) or those involving Cox-2 inhibitors could be the ones to provide answers for women with this menopausal status.

\section{References}

1 Sporn MB, Newton DL: Chemoprevention of cancer with retinoids. Fed Proc 1979;38:2528-34.

- Fisher B, Costantino JP, Wickerham DL, Redmond CK, Kavanah M, Cronin WM, Vogel V, Robidoux A, Dimitrov N, Atkins J, Daly M, Wieand S, TanChiu E, Ford L, Wolmark N: Tamoxifen for prevention of breast cancer: report of the National Surgical Adjuvant Breast and Bowel Project P-1 Study. J Natl Cancer Inst 1998;90:1371-88.

3 Powles T, Eeles R, Ashley S, Easton D, Chang J, Dowsett M, Tidy A, Viggers J, Davey J: Interim analysis of the incidence of breast cancer in the Royal Marsden Hospital tamoxifen randomised chemoprevention trial. Lancet 1998;352:98-101.

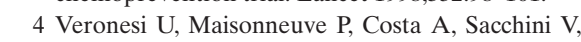
Maltoni C, Robertson C, Rotmensz N, Boyle P: Prevention of breast cancer with tamoxifen: preliminary findings from the Italian randomised trial among hysterectomised women. Italian Tamoxifen Prevention Study. Lancet 1998;352:93-7.

$>5$ Cuzik J, Forbes J, Edwards R, Baum M, Cawthorn S, Coates A, Hamed A, Howell A, Powles T: IBIS Working Party: First results from the IBIS Breast Cancer Prevention Trial. Lancet 2002;360: 817-824.

6 Cuzick J, Powles T, Veronesi U, et al.: Overview of the main outcomes in breast-cancer prevention trials.. Lancet 2003;361:296-300.

7 Cummings SR, Eckert S, Krueger KA, Grady D, Powles TJ, Cauley JA, Norton L, Nickelsen T, Bjarnason NH, Morrow M, Lippman ME, Black D, Glusman JE, Costa A, Jordan VC: The effect of raloxifene on risk of breast cancer in postmenopausal women: results from the MORE randomized trial. Multiple outcomes of raloxifene evaluation. JAMA 1999;281:2189-97.
8 Wenger NK, Barret-Connor E, Collins P, Grady D, Kornitzer M, Mosca L, Sashegyi A, Baygani SK, Anderson PW, Moscarelli E: Baseline characteristics of participants in the Raloxifene Use for The Heart (RUTH) trial. Am J Cardiology 2002;90: 1204-10.

9 Initial Results of the Study of Tamoxifen and Raloxifen (STAR) released: Osteoporosis drug raloxifen shown to be as effective as tamoxifen in preventing invasive breast cancer. National Institute of Health News, 17th April 2006.

10 Suh N, Glasebrook AL, Palkowitz AD, Bryant HU, Burris LL, Starling JJ, Pearce HL, Williams C, Peer C, Wang Y, Sporn MB: Arzoxifene, a new selective estrogen receptor modulator for chemoprevention of experimental breast cancer. Cancer Res 2001;61: 8412-5.

11 Baselga J, Llombart-Cussac A, Bellet M, GuillemPorta V, Enas N, Krejcy K, Carrasco E, Kayitalire L, Kuta M, Lluch A, Vodvarka P, Kerbrat P, Namer M, Petruzelka L: Randomized, double-blind, multicenter trial comparing two doses of arzoxifene (LY353381) in hormone-sensitive advanced or metastatic breast cancer patients. Annals Oncol 2003; 14:1383-90.

12 Buzdar A, O’Shaughnessy JA, Booser DJ, Pippen JE Jr, Jones SE, Munster PN, Peterson P, Melemed AS, Winter E, Hudis C: Phase II, randomized, double-blind study of two dose levels of arzoxifene in patients with locally advanced or metastatic breast cancer. J Clin Oncol 2003;21:1007-14.

13 Ke HZ, Foley GL, Simmons HA, Shen V, Thompson DD: Long-term treatment of lasofoxifene preserves bone mass and bone strength and does not adversely affect the uterus in ovariectomized rats. Endocrinology 2004;145:1996-2005.
14 Breast Cancer Linkage Consortium: Pathology of familial breast cancer: differences between breast cancers in carriers of BRCA1 or BRCA2 mutations and sporadic cases. Lancet 1997;349:1505-10.

15 West CP, Baird DT: Suppression of ovarian activity by Zoladex depot (ICI 118630), a long-acting luteinizing hormone releasing hormone agonist analogue. Clin Endocrinol (Oxf) 1987;26:213-20.

16 Berglund G, Nystedt M, Bolund C, Sjödén PO, Rutquist LE: Effect of endocrine treatment on sexuality in premenopausal breast cancer patients: a prospective randomized study. J Clin Oncol 2001; 19:2788-96.

17 Jakesz R, Hausmaninger H, Kubista E, Gnant M, Menzel C, Bauernhofer T, Seifert M, Haider K, Mlineritsch B, Steindorfer P, Kwasny W, Fridik M, Steger G, Wette V, Samonigg H: Randomized adjuvant trial of tamoxifen and goserelin versus cyclophosphamide, methotrexate and fluorouracil: evidence for the superiority of treatment with endocrine blockade in premenopausal patients with hormone-responsive breast cancer. J Clin Oncol 2002; 20:4621-7.

18 FitzGerald GA, Patrono C: The coxibs, selective inhibitors of cyclooxygenase-2. N Engl J Med 2001; 345:433-42.

19 Howe LR, Subbaramaiah K, Brown AM, et al.: Cyclooxygenase-2: a target for the prevention and treatment of breast cancer. Endocr Relat Cancer 2001; 8:97-114.

20 Schnitzer TJ: Cyclooxygenase-2-specific inhibitors: are they safe? Am J Med 2001;110:S46-S49.

21 Harris RE, Alshafie GA, Abou-Issa H, et al.: Chemoprevention of breast cancer in rats by celecoxib, a cyclooxygenase 2 inhibitor. Cancer Res 2000;60: 2101-3.

22 Mellemkjaer L, Linet MS, Gridley G, et al.: Rheumatoid arthritis and cancer risk. Eur J Cancer 1996; 32A:1753-7. 